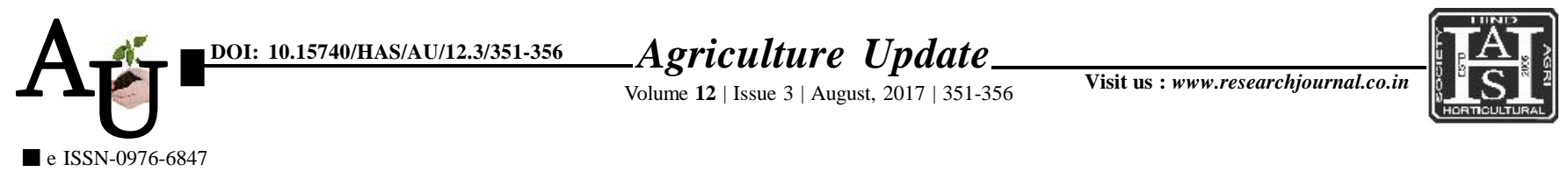

\title{
Research article: Constraints in adoption of recommended button mushroom cultivation techniques
}

GURDARSHAN SINGH AND GURMEET SINGH

Article Chronicle : Received :

28.02.2017;

Revised :

07.06.2017;

Accepted :

21.06.2017

KeY Words :

Constraints, Trainees, Training programme, Button mushroom

Author for correspondence :

GURDARSHAN SINGH

Krishi Vigyan Kendra, FARIDKOT (PUNJAB)

INDIA

Email:singhgurdarshan77

@ gmail.com

See end of the article for

authors' affiliations
SUMMARY : Mushroom cultivation as a subsidiary occupation provides ample opportunities for sustaining rural livelihood. Krishi Vigyan Kendra, Faridkot is actively involved in conducting training programmes on button mushroom cultivation. Main objective of training programmes on mushroom production is to promote mushroom production as a self employment venture which can ultimately improve the socio-economic condition of the poor. It has also been observed that some of the people trained at KVK, Faridkot have adopted mushroom cultivation while some have not. It was found worthwhile to study the major bottlenecks in adoption of mushroom cultivation as an enterprise. With this objective, the present study on constraints in adoption of recommended button mushroom cultivation techniques was carried out at Krishi Vigyan Kendra, Faridkot from 2011-15. A total of 62 trainees trained by KVK Faridkot from Faridkot and Kotkapura blocks of district Faridkot were selected as respondents. The data revealed that issues related to price fixation $(98 \%)$ and lack of government support (93.6\%) along with non-availability of quality spawn in the local area (84.9\%), it's untimely supply $(79.4 \%)$ and lengthy and cumbersome method of compost preparation for button mushroom $(80.3 \%)$ are the major bottlenecks in adoption of this venture: In order to find out the relationship between ranks accorded by groups of respondents to different categories of constraints, rank order correlation was calculated. It was found that category of marketing constraints $(82.70 \%)$ was the top ranked category as perceived by the growers engaged in mushroom production. This was followed by input constraints $(75.85 \%)$, technological constraints $(72.00 \%)$, general constraints $(64.46 \%)$ sociocultural constraints $(62.47 \%)$ and crop management constraints $(55.9 \%)$.

How to cite this article : Singh, Gurdarshan and Singh, Gurmeet (2017). Constraints in adoption of recommended button mushroom cultivation techniques. Agric. Update, 12(3): 351-356; DOI : 10.15740/HAS/AU/12.3/351356. 